\title{
Kim's Exclusion Argument Revisited
}

\section{Kim'in Dışarlama Argümanına Dair Bir İnceleme}

\author{
Özgür Demir ${ }^{1}$ (D)
}

${ }^{1}(\mathrm{PhD}$. Student), Istanbul University, Faculty of Letters, Department of Philosophy, Istanbul, Turkey

\section{ORCID: Ö.D. 0000-0003-1398-9009}

\section{Corresponding author/Sorumlu yazar: Özgür Demir \\ Istanbul University, Faculty of Letters, Department of Philosophy, Istanbul, Turkey E-mail/E-posta: ozgurdemir76@yahoo.co.uk}

Submitted/Başvuru: 08.08.2021

Revision Requested/Revizyon Talebi: 21.11.2021

Last Revision Received/Son Revizyon: 24.11.2021

Accepted/Kabul: 28.11.2021

Citation/Atıf: Demir, Ozgur. "Kim's Exclusion Argument Revisited." Felsefe Arkivi- Archives of Philosophy, 55 (2021): 67-83. https://doi.org/10.26650/arcp.980344

\begin{abstract}
Critical examination will be made firstly of the exclusion argument, famously developed by Jaegwon Kim, against nonreductive physicalism, and secondly of the identity solution as suggested by Kim himself for the exclusion problem allegedly prompted by his argument. I will argue that the argument is not so much of a trouble for nonreductive physicalism as Kim claims it to be, and that his purported solution is hardly convincing. For one thing, the principles, of which use are made in the argument, concern events, not properties. That is why the argument does not have a direct force to exclude properties. Second, the identification of mental and physical properties involves the idea that a functional property is to be at the same time a structural property, and, on the other hand, it amounts to a reflexive relation such that one and the same property is to realize itself, both of which ideas make little sense. Plus, a brief consideration will be made of the exclusion problem of how it is possible for mental properties to be causally relevant along with physical properties that always suffice for the effect. It will be suggested that mental properties can be causally relevant only if they are dependent upon physical properties, a suggestion which is based on the property-exclusion principle extracted from the principle of explanatory exclusion formulated by Kim himself.
\end{abstract}

Keywords: nonreductive physicalism, the exclusion argument, mental properties, physical realization, the exclusion problem

\section{Öz}

Bu makalede, Jaegwon Kim'in indirgemesiz fizikalizme karşı geliştirmiş olduğu ünlü dışarlama argümanı ve ayrıca bu argümanın yol açtığı iddia edilen dışarlama problemi için yine filozofun kendisinin önerdiği özdeşlik çözümü eleştirel olarak incelemeye tabi tutulacaktır. Söz konusu argümanın indirgemesiz fizikalizm için Kim'in iddia ettiği ölçüde bir sorun teşkil etmediği ve onun kendi çözüm önerisinin ise ikna edici olmadığı savunulacaktır. Çünkü, argümanın dayandııılığı ilkeler olaylara dair olup, özelliklere dair değildir. Argüman bu yüzden de herhangi bir özelliği dışarlama gücünden yoksun olmaktadır. Özdeşlik çözümüne gelirsek, zihinsel özelliklerle fiziksel özelliklerin özdeşlenmesi anlamsız görünen iki fikri içermektedir. Birincisi, bir kategori hatası içermektedir ki buna göre yapısal özelliklerin aynı zamanda işlevsel özellikler olması gerekmektedir. İkincisi, dönüşlü bir ilişki içermektedir ki buna göre bir özelliği realize eden özelliğin yine kendisi olması gerekmektedir. Bu noktalar 
detaylandırılıktan sonra, kısaca dışarlama problemi de ele alınacaktır. Yani, eğer fiziksel özellikler her zaman yeter koşul teşkil ediyorlarsa, bu durumda zihinsel özelliklerin nedensel olarak ilişkin olmaları nasıl mümkündür? Buna cevap aramak için öncelikle Kim'in açıklayıcı dışarlama ilkesi bir özellik dışarlama ilkesine dönüştürülecektir ya da örtük olarak içerdiği ilke açığa çıkarılacaktır. Daha sonra bu ilkeye dayanılarak, zihinsel özelliklerin nedensel olarak ilişkin olmalarının ancak fiziksel özelliklerle belli türden bir bağımlılık ilişkisine girmeleriyle mümkün olduğu bulunacaktır.

Keywords: indirgemesiz fizikalizm, dışarlama argümanı, zihinsel özellikler, fiziksel realize olma, dışarlama problemi

\section{Introduction}

It is fair to say that nonreductive physicalism has been, and still is, the mainstream position since its emergence in the 1970's, overshadowing other physicalist theories which are reductive, eliminative or epiphenomenalist about mental properties. On this position, mental properties, which are causally relevant properties, are though not identical with, yet dependent upon, physical properties by which they are realized. The preceding sentence includes the four characteristic theses of nonreductive physicalism. To them must be added the thesis, as it gives the theory its name, that psychological laws are essentially irreducible to, and therefore autonomous from, physical laws.

A brief clarification is appropriate of a few key terms, if only by way of illustration. A predicate, say, 'is $P$ ', is causally relevant insofar as it figures in causal explanations. A property is also said to be causally relevant when a cause satisfies the predicate 'is $P$ ' in virtue of having this property. An object satisfies the predicate 'is solid' in virtue simply of being solid. If a breaking of a glass by this object is truly explainable by this object's being solid, but not by its being red, then the property of being solid is causally relevant to the breaking of the glass, whereas the property of being red is not. A physical system that performs a function, is said to realize this function. In this sense, machines that perform arithmetical operations, realize these operations. That is to say, a concrete system makes real, or realizes, or materializes, or embodies an abstract entity-namely a function.

On the other hand, some properties of an object depend upon, and are determined by, its other properties. Thus, for example, the aesthetic properties of a painting are said to depend upon, and be determined by, its physical properties. In this sense, the former properties are said to supervene on the latter properties. Sometimes it is said that the properties of a whole supervene on the properties of its parts. Also, mental properties of events are said to supervene on their physical properties.

Nonreductive physicalism has a variety of forms some of which contain all of the theses mentioned above, whereas others may exclude either the thesis of supervenience or of realization. Being concerned rather with the realization thesis, we will not consider any further the thesis of supervenience. The rest of the three theses might be called the distinctness, the causal relevance, and the irreducibility. 
The exclusion argument developed particularly by Jaegwon Kim from the 1990's on seems to put nonreductive physicalism in trouble with regard to the causal relevance thesis. Although a variety of solutions are set forward to settle the problem allegedly prompted by this argument, none of them are seen to receive a general acceptance yet. So the causal relevance problem is in effect a matter of live philosophical controversy. First, I will argue that the exclusion argument, however, becomes clearly invalid when read according to the view on which events are conceived as particulars individuated by space-time regions they occupy. Second, I will also argue that the identity solution for the causal relevance problem proposed by Kim himself is hardly convincing. Finally, the causal relevance problem will be briefly considered, with the tentative result that mental properties can be causally relevant only if they are dependent upon physical properties. The relation of dependence per se having little explanatory value, it will be suggested, as a kind of dependence relation between mental and physical properties, the relation of realization, which I argue is apt to make intelligible the causal relevance of mental properties. Now before proceeding to Kim's argument, we shall look more closely at the relation of realization.

\section{What Is Realization? What Kind of Properties Are Realized?}

Objects and events alike have properties. That said, one need not think of properties as entities, as it were, attached to objects or events. For example, to say of an object that it has the property of roundness can be taken to mean simply that it is round, or to say of an event that it has the property of slowness, can be taken to mean simply that it is slow. The idea behind this, is the distinction between the object's parts, which are in and of themselves concrete, and the object's properties, which are in and of themselves abstract. The same goes also for events when they are conceived as concreta. ${ }^{1}$

There are different kinds of properties. Some of which are functional properties. e.g. being water-soluble, being elastic, and being dormitive, are properties such that each, so to speak, makes reference to a potential cause, to a potential change in an object that has it, and to a potential effect, respectively. Others are structural properties. e.g. being spherical, being red, and being slow are properties such that they, so to speak, make reference, unlike functional properties, to actual objects or events to which they belong. Thus, there must be a sort of epistemic aperture between functional and structural properties. Of course there are impure properties like the semirelational property of being brother which is taken to mean male sibling and from which we can

1 For a detailed discussion of events as concreta, see W. V. O Quine, "Events and Reification," in Actions and Events: Essays on the Philosophy of Donald Davidson, Ed. E. LePore and B. McLaughlin (Oxford: Basil Blackwell, 1985), 162-171. Quine suggests that events are identical when spatio-temporally co-extensive. This view is also adopted by Davidson afterwards. Compare Donald Davidson, "Reply to Quine on Events," in Actions and Events: Essays on the Philosophy of Donald Davidson, Ed. E. LePore and B. McLaughlin (Oxford: Basil Blackwell, 1985), 172-176 with Donald Davidson, "The Individuations of Events," in Essays in Honor of Carl G. Hempel, Ed. Nicholas Rescher (Reidel, 1969), 216-234. According to Kim, events are object's having a property at a time. On this view, events are identical when they are the same object's having the same property at the same time. See Jaegwon Kim, "Events as Property Exemplifications," in Action Theory, Ed. Myles Brand and Douglas Walton (Holland: D. Reidel Publishing Co., 1976), 159-177. As will be seen, how one construes event talks makes significant difference in reading the exclusion argument. If this is true, then Kim begs the question against those who do not share his conception of an event. 
infer some structural features about the object that has it. But in the limit case the aperture seems unbridgeable a priori. That is to say, merely and wholly from the purely functional properties of an object or event, we cannot figure out its structural properties; and, merely and wholly from the purely structural properties of an object, we cannot figure out its functional properties. ${ }^{2}$ It might be suggested as a counterinstance, for example, the fact that something is being used as a hammer betrays its being solid. But I think this does not necessarily follow, as there may be fluid substances usable in such a way in which they can fulfil functions ordinarily realized by using hammers.

We have said above that a concrete system realizes or materializes or embodies some function-an abstract entity. Since there is a sense in which an object realizes its functions it does in virtue of having some structural properties, so there is a sense in which functional properties are realized by structural properties, misleading sometimes though it may be. For, to say of an abstract entity that it realizes and materializes another abstract entity can be true only in a nonliteral and derivative sense. Certainly, what realizes or materializes a functional property is a concrete physical system itself, not its properties. Properties in themselves are abstract after all. Thus, a concrete physical system, in virtue of having so-and-so structural properties, has thereby at once such-and-such functional properties, causal roles, and causal powers; that is, it can realize, or execute, or exert such-and-such functions, or causal roles, or causal powers. When an object (or process, or event) that has a structural property, $S$, comes to exist, then an object (or process, or event) that has a functional property, $F$, comes to exist. One and the same object (or process, or event), under the circumstances, has both property $S$ and property $F$.

On the basis of the foregoing, therefore, our answer to the question what kind of properties are realized is roughly this: those are functional properties which are realized by structural properties, and not the other way around, if the realization thesis is to make sense when the realization relation is taken to be obtaining between properties. However, properties - whether structural or functionalcan also be said to be "instantiated" by concrete entities—namely objects and events.

Now, according to most nonreductive physicalist theories, all mental properties are nothing but functions or functional properties, and are realized, or materialized, or performed, by physical systems or processes - e.g. central nervous system or neurophysiological processes. Thus, on such

2 The distinction between functional and structural properties will not be articulated here. However there is a vast literature about it. For more details, I only refer readers, for example, to Jaegwon Kim, "Psychological Supervenience," Philosophical Studies 42(1982), 51-70, and David K. Lewis, "Extrinsic Properties," Philosophical Studies, 44(1983), 197-200. Subtleties aside, functional properties are also called causal, or relational, or extrinsic, or second-order, or dispositional properties, whereas structural properties are also called qualitative, or non-relational, or intrinsic, or first-order, or categorical properties. The question whether functional properties are second-order or first-order properties, depends upon the question whether functional properties are properties of properties of objects, or simply properties of objects themselves. If the former is the case, then they are second-order properties. If the latter is the case, and I presuppose it is, then they are first-order properties. For example, what is dormitive, or what comes to the same, what is capable of causing sleep, is the object itself, not its properties. Again, what is water-soluble, or capable of being solved by water, is the object itself, not its properties. Even though I regard causal relata as events, I speak freely as if they are objects themselves. I also use the words 'predicate' and 'property' nearly interchangeably, although it is argued by notable philosophers that objects might have properties for which we have not coined any term yet. But nothing crucial in the present work turns on it. 
a view, the same epistemic aperture described above must hold between mental and physical properties, either. And if mental properties are purely functional properties, then the aperture in this case will be unbridgeable. (Hence, the perennial dispute as to whether mind is a physical or non-physical substance.) That is, however great deal of psycho-functional information we may gather about our nervous system or neurophysiological processes, we would not possibly have any structural information about them, if we never observed them directly; and however great deal of structural information we may gather about our nervous system or neurophysiological processes, we would not possibly have any information about our psychological properties, if we never observed the higher-level causal relations - e.g. perception, thinking, action, and the like - that we enter into with the world in virtue supposedly of our nervous system or neurophysiological processes. ${ }^{3}$ In this respect, it does not seem trivial to show the extent to which the realization thesis as described here square with the not-yet-exactly-illuminated phenomenon called introspection or inner sense in the philosophical or psychological literature.

Finally, if mental properties are functional properties, then they might be realized by diverse natural species and even by artifacts already developed or yet to be developed in the future. In this sense, mental properties are said to be multiply realizable properties. To discuss whether all mental properties really are mere functions or not, is far beyond the scope of this paper. Now we turn to Kim's exclusion argument.

\section{Introduction to the Exclusion Argument}

Kim gives his argument time and again in a number of places. ${ }^{4}$ The exclusion argument and its close relatives ${ }^{5}$ have been, and are still, discussed by philosophers, and various proposals are suggested to circumvent it. The argument will be discussed here in two stages, the second being more detailed than the first. To put the exclusion problem roughly, when event $A$ causes event $B$, how can the mental properties of $A$ be causally relevant in the sense described above? Suppose that an event occurs which has the property of being a headache and the neurological property of some type, and that it causes us to ingest aspirin. In this case, its neurological property seems

3 The idea emphasized here is put in a slightly different way and defended at length by David Armstrong, $A$ Materialist Theory of Mind (New York: Routledge \& Kegan Paul, 1968).

4 Jaegwon Kim, "The Myth of Nonreductive Physicalism," Proceedings and Addresses of the American Philosophical Association 63(1989a), 279-284, Jaegwon Kim, "The Nonreductivist's Troubles with Mental Causation," in Mental Causation, Eds. Alfred Mele and John Heil (New York: Oxford University Press, 1993), 351-356, Jaegwon Kim, "Postscripts On Mental Causation," in Supervenience and Mind, Ed. Jaegwon Kim (New York: Cambridge University Press, 1995a), 360-361, Jaegwon Kim, "What is the Problem of Mental Causation," in Structures and Norms in Science, Eds. M. I. Chiara et al (Kluver Academic Publishers, 1997a), 322-325, Jaegwon Kim, Physicalism or Something Near Enough, (New York: Princeton University Press, 2005), 15-22, 39-45. All page references are to their reprints in Kim, Jaegwon, Supervenience and Mind except for Kim, Jaegwon, "What is the Problem of Mental Causation," and Kim, Jaegwon, Physicalism or Something Near Enough.

5 See, to cite just a few, Ted Honderich, “The Argument for Anomalous Monism," Analysis 42(1982), 52-64, Ernest Sosa, "Mind-Body Interaction and Supervenient Causation," Midwest Studies in Philosophy 9(1984), 276-281, Fred Dretske, "Reasons and Causes," Philosophical Perspectives 3(1989), 1-15, Brian McLaughlin, “On Davidson's Response to the Charge of Epiphenomenalism," in Mental Causation, Eds. Alfred Mele and John Heil (New York: Oxford University Press, 1993), 27-40. 
already to suffice causally for the ingestion of the pill, no matter if it has the property of being a headache or not. So the question is, how is it possible for mental properties to have causal relevance at all, if physical ones always suffice for the effect? The exclusion argument has us somehow ask this question.

Kim puts the argument in terms sometimes of the supervenience relation, and sometimes of the realizationn relation. It is in the latter terms that we shall examine it. Now, because, among other defects, Descartes's substance dualism was thought to constitute an overwhelming hindrance to accounting for the causal interaction between soul and body, some philosophers decided that the former must be nothing over and above the latter. They had therefore come to attribute all mental features to body. But the only advantage of this maneuver was to transform the problem of causal interaction at substance-level into the same problem at event-level. The next step was to identify mental events with physical events by the argument from mental anomalism developed by Donald Davidson. So the question how mental events can cause physical events ceased to be a problem. For, although mental properties cannot be reduced to physical properties, nevertheless mental events are physical events after all. But what we are after is not merely to establish the causal efficacy of mental events, but also the causal relevance of mental properties. That is, we need to show that mental events have causal effects in virtue of their mental properties. One may at once suggest that then we should also identify mental properties with physical properties to solve the problem radically. This is true in one sense (more on this at the end), but matters proved not that simple, as we shall see later.

Making our way to the details of the argument, let's recall the three theses that characterize nonreductive physicalism:

(1) Distinctness: Mental properties cannot be identified with physical properties.

(2) Causal Relevance: Mental properties are causally relevant in the sense that mental events cause, and are caused by, physical or mental events in virtue of their mental properties.

(3) Realization: Mental properties are realized by physical properties.

In addition to them, Kim gives a principle usually held by nonreductive physicalists as well:

(4) The Physical Closure Principle: If a physical event has a cause at $t$, it has a physical cause at $t$.

Sometimes this principle is described as the closure of the physical domain under the relation of causality. That is, any event that enters into causal relation with one of the events going on in the physical domain is itself an event going on in that domain. The former formulation, being weaker than this, describes the physical domain although not as a closed system but as a selfcontained one, and is fortified by the following principle:

(5) The Non-Overdetermination Principle: No event can have more than one synchronous and sufficient cause. 
This principle is not entailed, though, by the second formulation of the closure principle. For convenience, we may use the phrase 'the closure principles' to jointly refer to (4) and (5).

Now, Kim invites us to suppose that a mental event, $A$, causes a physical event, $B$. Event $B$ must have a physical cause by the physical closure principle; call this event $C$. Kim asks: what relation must obtain between $A$ and $C$ ? We can rule out two alternatives. The first is that $A$ and $C$ are severally necessary and jointly sufficient causes of $B$. For this violates the physical closure principle. The second is that, $A$ and $C$ are wholly distinct and severally sufficient causes of $B$. This, too, is inadmissible, because it is at variance with the non-overdetermination principle. So it seems impossible for $A$ to participate in the causal interaction involved. Kim calls this the exclusion problem. For, in any case, of the causes the physical one excludes the mental one on the strength of the principles in question.

But there is a third alternative. The mental event $A$ is identical with the physical event $C$. But, as noted earlier, our main purpose is to seek to establish that mental events cause physical ones in virtue of their mental properties. From this, Kim draws the conclusion that what we must identify are also the mental and physical properties of identified events. But this route is barred to nonreductive physicalists. Hence, nonreductive physicalists must perforce abandon either of the two principles. ${ }^{6}$

Here, however, it is really unclear why the only way towards any solution lies in identifying mental and physical properties. One might think that the physical properties of events exclude their mental properties on the strength of the closure principles. Let us notice, however, that these principles concern events, not properties. So the property-exclusion is possible only with the aid of additional principles which are not given in Kim's text under discussion. Thus the argument just discussed is not a property-exclusion argument. It may even be that this argument that is capable of excluding events, cannot be converted into a property-exclusion argument simply by putting the word 'property' in some places where the word 'event' occurs. ${ }^{7}$ The reason may be that abstract entities like properties are not subject to the same principles to which concrete entities like events are subject.

Since Kim has developed more elaborate and explicit versions of this argument in subsequent years, we have a chance to examine it in more details. We shall go into those details now.

\section{The Exclusion Argument In Details}

The argument begins with a simple supposition: an event that instantiates a mental property, $M$, causes an event that instantiates a mental property, $M^{*}$. More concisely:

(a) The $M$-instance causes the $M^{*}$-instance.

6 Kim, Jaegwon, "The Myth of Nonreductive Physicalism," 279-284.

7 See, for example, Stephen Yablo, "Mental Causation," The Philosophical Review 101(1992), 247-248. He proposes to obtain a property-exclusion argument from an event-exclusion argument by substituting the word 'property' for the word 'event' in certain places. 
Kim goes even further in the matter of abbreviation, and just says that $M$ causes $M^{*}$. Of course this abbreviation is harmless and makes for simplicity as long as it is clear in the context whether the letters stand for a property or an event.

Kim then proceeds by saying to the effect that property $M^{*}$, by (3), must be realized by a physical property, say, $P^{*}$. That is:

(b) Property $M^{*}$ is realized by property $P^{*}$.

Now the question is, why did the $M^{*}$-instance occur? And it appears that we have two distinct and mutually exclusive answers: (i) the $M$-instance caused it, and (ii) $P^{*}$ realized it. According to Kim, there is a tension, due to a kind of overdetermination, between these two scenarios. Because, the $M^{*}$-instance already has a physical realizer, $P^{*}$, which is sufficient for it. So the $M^{*}$-instance would have occurred no matter whether the event having property $M$ had occurred before. This defeats $M$ s claim to be the cause of the $M^{*}$-instance. But there is, so Kim says, a way of saving $M$. The $M$-instance might be said to cause $M^{*}$ indirectly-i.e. through what Kim calls downward causation. That is:

(c) The $M$-instance causes the $M^{*}$-instance by causing the $P^{*}$-instance.

Thus can be saved the $M$-instance's claim to be the cause of $M^{*}$. But matters do not come to an end here. For, since $M$ is a mental property too, it should also be realized by a physical property, say, $P$. According to Kim, if $P$ is sufficient for $M$, it is sufficient for $P^{*}$ also. For, $P$ realizes $M$ after all. Thus:

(d) $\quad M$ caused $P^{*}$ and $P$ caused $P^{*}$.

Now, $M$ and $P$, by (1), cannot be identical with each other:

(e) $M \neq P$.

By (5), $M$ and $P$, being synchronous, cannot be severally sufficient causes of $P^{*}$. (Note the shift from talk of properties to talk of causes.) So:

(f) $P^{*}$ is not overdetermined by $M$ and $P$.

And, $P$ excludes $M$ on the strength of (4):

(g) $P^{*}$ s cause is $P$ and not $M$.

(h) Therefore, $M$ is causally irrelevant.

By means of this argument, a nonreductive physicalist who holds (4) and (5), is forced to abandon (2). And as an only way out of this difficulty it is suggested to abandon (1)-i.e. to adopt the idea that mental properties are identical with physical properties. We will consider the possibility of such an identity. But before doing this, we shall understand what this argument really means. 
Some premises seem to lead us to draw the conclusion that mental properties are causally irrelevant. So we get back to the question mentioned at the outset of the present section: How is it possible for mental properties to be causally relevant at all? This argument in one form or another has been taken seriously by many philosophers. And in order to find an answer to the question allegedly prompted by it, they have constructed ingenious theories postulating a variety of entities such as property instances, tropes, and essences. Having observed that objects and events have countless properties, whether relevant or irrelevant in causal contexts, they seek to find such fine-grained entities in addition to, or instead of, objects and events as can be said to include just desired properties and exclude the undesired ones. But these theories have been criticized in certain counts. First, some of these entities, however fine-grained they may be, inevitably include some undesired properties, and the others, being exceedingly fine-grained, exclude some desired properties. Second and what is worse, the same question still can be asked, whether these entities (essences excluded) are causally relevant in virtue of their mental aspects or in virtue of their physical aspects? Although it would be really instructive to consider all of these theories at length and of course this would do more justice to them, nevertheless that takes us way beyond the intended scope of the article.

Now, let us examine the argument without abbreviations and on the conception according to which events are concreta. An event that instantiates property $M$ causes an event that instantiates property $M^{*}$. So the $M$-event is, by hypothesis, the sufficient cause of the $M^{*}$-event. On the other hand, property $M^{*}$, by (3), is realized by property $P^{*}$ (or better, realized by the event that instantiates property $P^{*}$ ). So a sufficient condition for the $M^{*}$-event's being an event instantiating property $M^{*}$ is for it to be an event instantiating property $P^{*}$. Now, there seems to be no tension at all between the fact that the $M$-event is the sufficient cause of the $M^{*}$-event and the fact that property $P^{*}$ is the sufficient condition of property $M^{*}$. So there is no need for reconciliation. There is also no need to formulate (c) to save the $M$-event's claim to be the cause of the $M^{*}$-event, and, for that matter, no need to postulate the notion of "downward causation." Because,

(c') The event that has property $M$, caused the event that has both property $M^{*}$ and its realizer property $P^{*}$.

Furthermore, in the light of (c') we revise (d) as follows:

(d') The event that has both property $M$ and its realizer property $P$, caused the event that has both property $M^{*}$ and its realizer property $P^{*}$.

Now it is hard to see how physical properties exclude mental ones as per the closure principles. If the letters ' $M$ ' and ' $P$ ' that occur in (e), stand not for events, but for properties, and therefore (e) expresses that property $M$ is not identical with property $P$, then (e) is true by (1). However, right after this step we see Kim trying to exclude $M$ on the strength of the closure principles. But, as noted earlier, these principles concern events, not properties, and therefore cannot apply to properties. Thus, property $P$ cannot exclude property $M$ on the strength of the closure principles, of course unless ' $P$ ' and ' $M$ ' stand for events. If they do, then it follows that $P$ is already identical 
with, and therefore cannot exclude, $M$ (i.e. $P$ itself), and that (f) is trivially true. Furthermore, in this case, (g) turns into a falsity. As a result of all these considerations, if $P$ and $M$ are identical, then one and the same event cannot exclude itself; if $P$ and $M$ are distinct, then one property cannot exclude the other as per the closure principles. In both cases, we fail to advance to (h). So (h) is a non-sequitur; the argument is invalid, and it does not exclude whatever it is intended to exclude, if events are conceived as concreta. Besides, in this case, the exclusion argument is not so much of a trouble for nonreductive physicalism as Kim claims it to be.

So where does this examination thus far conducted leave us? The main task of the article seems to be fulfilled - to show that the exclusion argument as framed by Kim does not make much trouble for non-reductive physicalism. As can be seen, the identification of mental and physical properties is not the only way to save mental properties from exclusion by physical properties; another is to conceive events as particulars. However, as far as inclusion (by physical proeprties) of mental properties is concerned-i.e. to establish causal relevance of mental properties along with physical ones-no progress has been made yet. This is not surprising because the closure principles concern events and so we need additional principles. Now we shall proceed to Kim's solution to see if we can draw some lessons from it.

\section{Kim's Solution}

Kim began to develop his argument from the early 1990's on. His identity solution first appears in 1995 and is elaborated on to some extent in 1997. However, this solution, according to Kim, only applies to some mental properties and the rest appear intractable. For, what Kim calls phenomenal properties such as pain, consciousness, and the like, do not seem, according to him, functional properties. ${ }^{8}$

As is well-known, before the emergence of nonreductive physicalism in the 1970's, the prevalent approach to the mind-body problem in philosophical circles was the classical identity theory, a.k.a. type-identity theory, that itself emerged in the early 1960's. According to this theory, each mental property is identical with one, and only one physical property. To illustrate, the property of being pain is identical with the property of being a c-firing. However, the argument from anomalous monism developed by Donald Davidson and the multiple realization argument advanced by Hilary Putnam are thought to have discredited type-identity theory. Very roughly put, on the multiple realization argument, for example, mental properties can be realized by diverse physical properties. If type-identity theory were to be true, then those diverse physical properties would have to be identical with each other. But they are not, thus type-identity theory must be false.

What Kim does, only consists of trying to accommodate type-identity theory to the multiple realization phenomenon, and rechristening it multiple-type physicalism. Thus, for Kim, mental properties are identical with physical properties relativized to species. To use the same example,

8 Kim, Jaewgon, "Postscripts on Mental Causation," 366-367, and Jaegwon Kim, "Mind-Body Problem: Taking Stock After Forty Years," Nô̂s, 31(1997b), 203-204. 
being pain is identical with being a c-firing in humans, with being a d-firing in reptiles, with being an e-firing in molluscs, and so on. On this view, if a physical property is causally relevant, so is the mental property with which it is identical. However, were the only obstacle in the way of the identity strategy to be the phenomenon of the multiple realization, this approach might have paved the way towards a solution. But another, and to me the principle, barrier is this, that mental properties are, by hypothesis, functional properties, and are realized by physical properties, which are structural properties. There is little sense in which the same property (i.e. an abstract entity) is both a functional property and a structural property, and in which the same property is realized by itself.

Kim's line of reasoning is this: Suppose a mental property, $M$, is realized in different species by physical properties $P_{1}, P_{2}$, and $P_{3}$. In this case, argues Kim, each $M$-instance is either a $P_{1}$ instance, or a $P_{2}$-instance or a $P_{3}$-instance. This is because, unless I am mistaken, that property $M$ is identical with $P_{1}$ in one species or with $P_{2}$ in another species or with $P_{3}$ in still another species. In short, property $M$ is, as Kim puts it, 'disjunctively' identical with $P_{1}, P_{2}$, and $P_{3}{ }^{9}$ In this way, the exclusion problem dissolves as well; for, since the instances (events, procceses, states) ${ }^{10}$ are identical, they cannot exclude one another.

In a subsequent work two years later, Kim, perhaps having realized the incoherence in identifying functional and structural properties, asks the following question:

We must now confront the following question: if $M_{\mathrm{i}}$ is a second-order property and $P_{\mathrm{i}}$ a first-order property, or if $M_{\mathrm{i}}$ is a causal role and $P_{\mathrm{i}}$ is the occupant of that role, how could they be one and the same thing? Isn't it incoherent to think that a property could be both first-order and second-order, both a role and its occupier? A good question! ${ }^{11}$

However Kim's strategy in answering this question seems to involve more incoherence than the one he tries to dissolve. It is this, that thinking of a property, as it still remains a property, to be at the same time something like an object or event. Therefore the same property, under the circumstances, will be able to satisfy more than one first-order predicate or description just as objects and events do. ${ }^{12}$ Thus, one and the same property will satisfy both 'is $M^{\prime}$ and 'is $P_{1}$ ' in one case, and both 'is $M^{\prime}$ and 'is $P_{2}$ ' in another, and both 'is $M^{\prime}$ and 'is $P_{3}$ ' still in another, and so on. Here a property is regarded to be an extraordinary entity such that not only is it treated as a property capable of being had by objects but at the same time as a kind of object capable of satisfying first-order predicates. If this idea does not seem appealing, one might try the others.

\footnotetext{
9 Note that if events are regarded as concreta, there is no need to identify (disjunctively or not) property $M$ and property $P_{\mathrm{i}}$ so as to be able to say that the $M$-instance is identical with the $P_{\mathrm{i}}$-instance.

10 Kim, Jaegwon, "Postscripts on Mental Causation," 364. Kim himself says there that instances are particulars like events, states, and processes.

11 Kim, Jaegwon, "Mind-Body Problem: Taking Stock After Forty Years," 200.

12 Kim, Jaegwon, “Mind-Body Problem: Taking Stock After Forty Years," 201.
} 


\section{In Search of Solution}

We have observed that the exclusion argument does not have the direct force, or principle, of excluding one property in favor of the other, regardless of how one conceives events. If we do not have such a principle to exclude properties, then obviously we also do not have a direct reason to claim that physical properties exclude mental ones. Now in search of such a principle, let us consider the principle of explanatory exclusion formulated by Kim himself. It is as follows: "No event can be given more than one complete and independent [causal] explanation."13 (Italics are original.)

The word 'causal' does not occur in Kim's formulation. But the context is clear to show that what is meant is causal explanations. Now, causal explanations invoke properties of causes and effects. Therefore, retaining the concept of independence, but reconceiving the notion of completeness as that of sufficiency, we might reformulate this principle. What I have in mind is the following:

(6) The Principle of Property Exclusion: If a property, $P$, of a cause, $c$, is sufficient for a property, $S$, of an effect, $e$, then no property $M$ independent of $P$ is either sufficient or necessary for $S$, where $c$ is the sufficient cause of $e$. Thus, $c$ 's other properties independent of $P$ is neither sufficient nor necessary for $c$ to cause $e$ to have $S$.

Various property exclusion principles have been formulated in the literature. Here we consider just two of them. The first comes from Yablo, and it reads thus, "If a property $X$ is causally sufficient for an event $y$, then no property $X^{*}$ distinct from $X$ is causally relevant to $y$." ${ }^{14}$ This principle seems to harbor two presumptions. First, it is assumed that the causal relevance is a relation borne to events by properties. Though Yablo says immediately that he tries to remain neutral about this matter. But it proves crucial, as we will see shortly. Secondly and more importantly, it holds necessary for $X^{*}$ not to be distinct from $X$ in order for it to be causally relevant. If two properties are not distinct, then are they identical? Are we supposed to specify the identity conditions of properties? Perhaps the right word we need here is not 'distinct'. For example, being red and being scarlet are presumably distinct properties, then are we to say that if either of them is causally relevant, then the other is not? But if being scarlet of a cause is necessary and sufficient condition for an effect's being so-and-so, then being red is a necessary condition for it. Conversely, if being red of a cause is a necessary and sufficient condition for an effect's being so-and-so, then being scarlet is a sufficient condition for it. In each cases, two distinct properties are clearly causally relevant. It is then evident that this principle as such is, at best, stronger than needed, as Yablo himself pointed out. ${ }^{15}$

The second is formulated by the MacDonalds, which is this: "If a property, $P$, of a cause, $c$, is causally sufficient for an effect, $e$, then no other property, $Q$, distinct from and independent of

13 Jaegwon Kim, "Mechanism, Purpose, and Explanatory Exclusion," Philosophical Perspectives 3(1989b), 239.

14 Yablo, Stephen, "Mental Causation," 247.

15 Yablo, Stephen, "Mental Causation," 259. 
$P$, is causally relevant for $e . "{ }^{16}$ This is nearly the same as the former except for a crucial difference that one property is not to be causally relevant which is distinct and independent from the causally relevant property. Of course this means that if a property distinct from the causally relevant property is to be causally relevant too, then the former must not be independent from the latter. But since the identity of mental and physical properties is already ruled out by (1), we do not need to include the word 'distinct' in our formulation. Furthermore, I take the relation of causal relevance to be one which relates properties of causes to properties of effects. Hence the principle (6).

Now that we have our property exclusion principle at hand, we can legitimately say that one property of an event excludes another on the strength of (6), if the second property is independent from the first. Being dependent, however, does not guarantee causal relevance according to (6). It is only a necessary condition. Thus, our necessarily modest and tentative answer for the question of how it is possible for mental properties to be causally relevant at all is the following:

(7) Mental properties might be causally relevant properties only if they are dependent upon physical properties.

Given (1)-(6), the whole question of causal relevance of mental properties thus boils down to (7). That is to say, it reduces to the question whether mental properties depend upon physical properties or not. Now it should be admitted that the relation of dependence per se has low explanatory value, and simply qualifying it as a metaphysically necessary dependence makes it no more explanatory. Nor does it make it so to call it supervenience. ${ }^{17}$ So let us look around for the kinds of dependence relation which makes it intelligible why mental properties can have causal relevance along with physical properties.

One of the relations of dependence that first comes to mind is the relation of realization. We have seen that a functional property might be instantiated by an object only if some structural property is instantiated by that object. This depicts the relation of realization as a kind of dependence relation. Let us look at it in a toy example. In the case of a pill's causing sleep, its property of being dormitive and the property of its being of so-and-so chemical compound are each a sufficient condition of the event of sleeping, and both explain why the sleeping took place. (Being dormitive might have significant explanatory value on occasion, and explanatory value of mental properties is, I take it, beyond doubt.) So, does it make sense to say that even if the pill had not been dormitive, it would still have caused people to fall asleep on the grounds that its being of so-and-so chemical compound is already a sufficient condition? The same goes for all functional properties (the mental ones included, of course if (3) is true). Maybe it will still be insisted that the chemical property excludes the functional property, the latter being determined by the former. But let's not think of properties as object-like entities so as not to imagine that one would exclude the other in such a case.

16 Cynthia MacDonald and Graham MacDonald, "The Metaphysics of Mental Causation,” The Journal of Philosopy, 103(2006), 544.

17 For a detailed discussion why the supervenience relation cannot be explanatory, see Kim, Jaegwon, "Supervenience and Mind," 165-169, and Kim, Jaegwon, "Mind-Body Problem: Taking Stock After Forty Years," 189-194. 
Perhaps it should be pointed out here again that the notion of a sufficient condition (i.e. a property) is separated from that of a sufficient cause (i.e. an event). For one thing, while one of the sufficient causes excludes the other by the closure principles if they are distinct, one of the sufficient conditions does not exclude the other by (6) even if they are distinct, but only if either of them depends on the other. For example, if the property of being green and the property of being spherical, being logically (and nomologically) independent properties, each lays claim to be a sufficient condition for something, the one that proves its claim, excludes the other by (6).

To see more clearly that (6) quite appropriately asserts the relation of dependence not to guarantee causal relevance, suppose that the same pill is both dormitive and nauseous, and that these properties, being functional properties, are realized, as it happens, by the same structural property. If the event to be explained is an event of sleeping, then the property of being nauseous, though realized by the same property, is not causally relevant, and does not explain the event with regard to its being a sleeping event. The property realized-i.e. the functional property-must be logically related to that property of the effect in terms of having which it is to be explained. While the property of dormitivity bears such a relation to the property of sleeping, the property of being nauesous does not. But if the event to be explained were to be a nausea, the case would be the converse.

In the course of our examination it becomes more and more clear that to take the relation of causal relevance as relating properties of causes to properties of effects is usually of crucial importance. Because, while one property of cause may be relevant to, or makes it intelligible, why the effect is such-and-such, it may not so for another property of it. It may also be that two properties of cause are each causally relevant to, or a causally sufficient condition for, or makes intelligible, the same property of effect, as in the examples earlier given. In those cases, the two properties can be said to be causally co-relevant properties.

However, two causally co-relevant properties might be both structural (qualitative) properties. This possiblity takes us out of the mental causation problem, if mental properties are all functional properties of course.

If two co-relevant properties are both structural (or qualitative), then one of them might be more specific than, or is identical with, the other. For example, take the property of being red and the property of being scarlet. This is the relation of determination. Another example for the same relation is the property of being triangle and the property of being equilateral triangle (although some kinds of triangles are not mutually exclusive). The property of being red and the property of being scarlet, as has been shown above, might be co-relevant properties. The relation of determinate to determinable is arguably a kind of dependence relation. Nothing can be scarlet without being red, and being scarlet is a sufficient condition for being red. Properties, being abstract entities, might be said to have logical (or nomological) connections between each other.

Now it might be instructive to discuss the following example. Suppose that a glass breaks if one sings at more than $70 \mathrm{~dB}$ (in the viccinity). ${ }^{18}$ One day someone sings at $80 \mathrm{~dB}$, and

18 The example is from Yablo, Stephen, "Mental Causation," 259. 
consequently the glass breaks. The singing's property of being at $80 \mathrm{~dB}$ is a sufficient condition for the breaking of the glass, and, at the same time, it is seemingly a determinate of being at less than $90 \mathrm{~dB}$. Therefore being at less than $90 \mathrm{~dB}$ must also be causally relevant (at least a necessary condition) to the breaking of the glass. But we know it is not. For we cannot say that the glass broken because, or despite, the singing was at less than $90 \mathrm{~dB}$. But note that the property of being at less than $90 \mathrm{~dB}$ is also the property of being between at 90-70 dB or being between at 70-0 dB. However, disjunctive properties arguably are not determinable properties. ${ }^{19}$ So being at less than $90 \mathrm{~dB}$ is, contra Yablo, not determinable with respect to being at $80 \mathrm{~dB}$, and therefore cannot be said to be causally relevant on the grounds that the latter is.

In the second option, two co-relevant properties are identical. For example, temperature is mean molecular kinetic energy or light is electromagnetic radiation. If either of the properties is causally relevant, so too is the other. But to say of properties that they are identical, though in one sense is true, it is misleading. Predicates that express such scientifically identified properties are formed usually from general names of phenomena such as objects (countable or uncountable), states, or processes. The same phenomenon that is called by one name in a scientific discipline, is called by another name in another, or in the same, scientific discipline. So, what are identical are not properties, but phenomena called by different names in sciences.

If the examination done so far is correct, then it will turn out that if mental properties are physically realized functional properties, then the identity strategy is not a way of proving mental properties to be causally relevant, let alone the only way to doing it, notwithstanding what Kim claims to the contrary. The relation of realization is arguably a kind of dependence relation, which is the most distinctive thesis of nonreductive physicalism. Thus, on the property exclusion principle, physical properties by no means exclude mental properties that they realize, on the grounds merely of their already being sufficient conditions.

Before closing the discussion, there is a point that bears mention. Although mental properties, being functional properties, are topic-neutral in the sense that they can be realized also by nonphysical substances if any, yet there is a sense in which they are physical properties. For it makes them part of the physical domain that they are realized by physical properties in that domain. Put differently and more cautiously, if the realization thesis as described here is correct, then for all psychological predicates, there can in principle be found, case-by-case at least, physical predicates or a combination thereof that might truly replace them in appropriate contexts. On this score, and in a quite broad sense of the term, nonreductive physicalism might be said to be a reductive theory of the mind. But nonreductive physicalism also defends the thesis that psychological laws are essentially irreducible to, and therefore autonomous from, physical laws, on account of which it is a nonreductive hypothesis, in the strict sense of the term.

19 See, John Searle, "Determinables and the Notion of Resemblance," The Aristotelian Society Supplement 33(1959), 148. 


\section{Conclusion}

The heart of our research lies in the fact that the exclusion argument developed by Kim can exclude events and not properties. For, the principles, which are put together in the argument, apply to events, not properties. In other words, those are events, not properties, that can be subjected to the principles in question. If what is at issue is to be the exclusion of properties, then we need a principle that concerns properties, and we have formulated such a principle that we have called the principle of property-exclusion, and have shown that mental properties can be exempt from it in virtue of being realized by, and therefore, dependent upon, physical properties. An important finding of our research, not novel though it is, is that the relation of causal relevance should be taken to be relating properties of causes to properties of effects. Our search of solution, sketchy and non-exhaustive as it is, have shown, I believe, that properties, which bear some kinds of relation of dependence to causally relevant properties, can themselves also be causally relevant. In other words, an event, qua being such-and-such, might be given more than one causally sufficient condition, and therefore more than one causal explanation, provided they bear a relation of dependence of a kind to one another, being in keeping with Kim's principle of explanatory exclusion. ${ }^{20}$

Peer-review: Externally peer-reviewed.

Conflict of Interest: The author has no conflict of interest to declare.

Grant Support: The author declared that this study has received no financial support.

Hakem Değerlendirmesi: Dış bağımsız.

Çıkar Çatışması: Yazar çıar çatıșması bildirmemiș̦tir.

Finansal Destek: Yazar bu çalışma için finansal destek almadığını beyan etmiştir.

\section{References}

Armstrong, David. A Materialist Theory of the Mind. New York: Routledge \& Kegan Paul, 1969.

Davidson, Donald. "Reply to Quine on Events." Actions and Events: Essays on the Philosophy of Donald Davidson. Ed. E. LePore and B. McLaughlin, 172-176. Oxford: Basil Blackwell, 1985.

Davidson, Donald. "The Individuation of Events," Essay in Honor of Carl G. Hempel. Ed. Nicholas Rescher, 216-234. Reidel, 1969.

Dretske, Fred. "Reasons and Causes." Philosophical Perspectives, 3(1989): 1-15.

Honderich, Ted. "The Argument for Anomalous Monism." Analysis, 42(1982): 59-64.

Kim, Jaegwon, "Events as Exemplifications." Action Theory. Ed. Myles Brand and Douglas Walton, 159-177. Holland: D. Reidel Publishing Co., 1976.

Kim, Jaegwon. "Mechanism, Purpose, and Explanatory Exclusion." Philosophical Perspectives, 3(1989b): 77108. Reprinted 1995b: 237-264.

Kim, Jaegwon. "Mind-Body Problem: Taking Stock After Forty Years," Noûs, 31(1997b): 185-207.

20 Many thanks to one anonymous referee for the helpful comments and I would particularly like to express my indeptedness to John Heil for his advice on shaping the argumentation of this paper in some significant points. 
Kim, Jaegwon. "Postscripts On Mental Causation." Supervenience and Mind. Ed. Jaegwon Kim, 358-367. New York: Cambridge University Press, 1995a.

Kim, Jaegwon. "Psychophysical Supervenience.” Philosophical Studies, 41(1982): 51-70.

Kim, Jaegwon. "The Myth of Nonreductive Physicalism." Proceedings and Addresses of the American Philosophical Association, 63(1989a): 31-47. Reprinted 1995b: 265-284

Kim, Jaegwon. “The Nonreductivist's Troubles with Mental Causation.” Mental Causation. Ed. Alfred Mele and John Heil, 189-210. New York: Oxford University Press, 1993. Reprinted 1995b: 336-357.

Kim, Jaegwon. "What is the Problem of Mental Causation." Structures and Norms in Science. Ed. M. 1. Dalla Chiara et al, 319-329. Kluwer Academic Publishers, 1997a.

Kim, Jaegwon. Physicalism or Something Near Enough. New Jersey: Princeton University Press, 2005.

Kim, Jaegwon. Supervenience and Mind. New York: Cambridge University Press, $1995 \mathrm{~b}$.

Lewis, David. “Extrinsic Properties,” Philosophical Studies, 44(1983): 197-200.

MacDonald, Cynthia ve MacDonald, Graham. "The Metaphysics of Mental Causation.” The Journal of Philosophy, 103(2006): 539-576.

McLaughlin, Brian. “On Davidson's Response to the Charge of Epiphenomenalism.” Mental Causation. Ed. Alfred Mele and John Heil, 27-40. New York: Oxford University Press, 1993.

Quine, W. V. O. "Events and Reification." Actions and Events: Essays on the Philosophy of Donald Davidson. Ed. E. LePore and B. McLaughlin, 162-171. Oxford: Basil Blackwell, 1985.

Searle, John. "Determinables and the Notion of Resemblance." The Aristotelian Society, Supplement, 33(1959): $141-158$.

Sosa, Ernest. "Mind-Body Interaction and Supervenient Causation.” Midwest Studies in Philosophy, 9(1984): 276-281.

Yablo, Stephen. "Mental Causation.” The Philosophical Review, 101(1992): 245-280. 
